\title{
Effect of somatostatin on the sphincter of Oddi in patients with acute non-biliary pancreatitis
}

\author{
K-H Lai, G-H Lo, J-S Cheng, M-T Fu, E-M Wang, H-H Chan, Y-Y Wang, P-I Hsu, \\ $\mathrm{C}-\mathrm{K}$ Lin
}

\begin{abstract}
Background-Somatostatin has been used to prevent pancreatitis after endoscopic retrograde cholangiopancreatography but its effect on acute non-biliary pancreatitis is still unclear.

Aim-The purpose of this study was to evaluate the function of the sphincter of Oddi (SO) and the effect of somatostatin on patients with non-biliary pancreatitis. Methods-Twenty patients (18 males, two females) with acute pancreatitis (alcoholic 18 , idiopathic two) received SO manometry within one week after admission. After baseline measurement, a bolus dose of somatostatin (Stilamin, Serono) $250 \mu \mathrm{g}$ was infused slowly, and SO manometry was repeated after five minutes. Continuous infusion of somatostatin $250 \mu \mathrm{g} / \mathrm{h}$ was given for 12 hours after SO manometry. Serum amylase, lipase, glucose, and C reactive protein (CRP) levels were examined before and after somatostatin infusion.
\end{abstract}

Results-SO manometry was unsuccessful in six patients due to contracted sphincter. In the remaining 14 patients, high SO basal pressure (SOBP $>40 \mathrm{~mm}$ $\mathrm{Hg}$ ) was found in seven patients. After somatostatin infusion, mean SOBP decreased from 48.8 (29) to 31.9 (22) $\mathrm{mm} \mathrm{Hg}$ $(\mathrm{p}<0.01)$. One patient had a paradoxical reaction to somatostatin (SOBP increased from 30 to $50 \mathrm{~mm} \mathrm{Hg}$ ) while the other 13 patients had a fall in SOBP after somatostatin. One patient developed abdominal pain with a serum amylase level of 2516 IU/1 after SO manometry. No other side effects or changes in amylase, lipase, glucose, or CRP levels were observed in the other 19 patients after SO manometry and somatostatin infusion.

Discussion-Sphincter of Oddi dysfunction is common in patients with acute non-biliary pancreatitis and in most cases somatostatin can relax the sphincter. (Gut 2001;49:843-846)

Keywords: acute alcoholic pancreatitis; sphincter of Oddi; somatostatin

Gall stone disease, alcohol abuse, and sphincter of Oddi (SO) dysfunction are the common causes of acute pancreatitis. ${ }^{12}$ The action of alcohol on the SO is still controversial. According to some studies, alcohol induces SO relaxation $^{3}{ }^{4}$ but in another human study local instillation of alcohol into the duodenum resulted in an increase in SO motility. ${ }^{5}$ High SO basal pressure (SOBP) has been found in up to $89 \%$ of patients with idiopathic recurrent pancreatitis. ${ }^{6-8}$ Both natural somatostatin and its synthetic long acting analogue (octreotide) are potent inhibitors of pancreatic enzyme secretions but their effect on the diseased pancreas is still unclear. ${ }^{9-12}$ Previous studies have shown that somatostatin can relax the SO allowing free drainage of pancreatic secretions into the duodenum. ${ }^{13}{ }^{14}$ In a recent metaanalysis, somatostatin was found to be more cost effective than other agents in the prevention of pancreatic injury after endoscopic retrograde cholangiopancreatography. ${ }^{15} 16$ However, the action of somatostatin on the SO during the acute stage of pancreatitis is unclear. The purpose of this study was to investigate SO function and also to study the effect of somatostatin on patients with acute non-biliary pancreatitis.

Materials and methods

From July 1998 to December 1999, 144 patients with acute pancreatitis were admitted to Kaohsiung Veterans General Hospital. The causes of acute pancreatitis were gall stones in 69 patients, alcohol in 51, hyperlipaemia in 10, and idiopathic in 14 patients. Eighteen patients with acute alcoholic pancreatitis and two with acute idiopathic pancreatitis agreed to participate in our study. Alcoholic pancreatitis was defined as the presence of anatomical changes in the pancreas by computed tomography, having a history of ingesting $150 \mathrm{~g}$ of alcohol per day for more than five years, and no gall stones or other causes of pancreatitis. Two patients with idiopathic pancreatitis did not have alcohol abuse or gall stones.

SO manometry was performed in each patient within one week after admission. No medication except local anaesthesia of the throat with $8 \%$ xylocaine was given. SO manometry was performed using a triple lumen polyethylene catheter with a $1.7 \mathrm{~mm}$ outer diameter which was introduced through the biopsy channel of a duodenoscope (Olympus JF 1T20, Tokyo, Japan). The catheter was perfused with sterile distilled water at a rate of $0.25 \mathrm{ml} / \mathrm{min}$ by a pneumohydraulic capillary pump (Arndorfer Medical Specialties, Greendale, Wisconsin, USA). We calibrated the pressure of the catheter in the duodenal lumen to zero before cannulation. After deep cannulation, aspiration from one channel of the catheter was performed to confirm the correct

Abbreviations used in this paper: $\mathrm{SO}$, sphincter of Oddi; CRP, C reactive protein; SOBP, SO basal pressure; $\mathrm{CBD}$, common bile duct. 
Table 1 Patient characteristics

\begin{tabular}{ll}
\hline $\mathrm{n}$ & 20 \\
\hline Sex $(\mathrm{M} / \mathrm{F})$ & $18 / 2$ \\
Age (y) (mean (range)) & $41.7(27-61)$ \\
Alcoholic abuse & 18 \\
Serum cholesterol $>200 \mathrm{mg} \%$ & 9 \\
Serum triglyceride $>200 \mathrm{mg} \%$ & 9 \\
CT grading $(\mathrm{C} / \mathrm{D} / \mathrm{E})$ & $12 / 4 / 4$
\end{tabular}

CT, computed tomography.

position of the catheter. The catheter was considered in the pancreatic duct if no bile stained fluid was aspirated. Pressure was measured first in the pancreatic duct, and then in the SO and duodenum using the station pull through technique. After baseline measurements for three minutes, somatostatin $250 \mu \mathrm{g}$ (Stilamin, Serono, Switzerland) was infused intravenously over three minutes. SO manometry was repeated five minutes after somatostatin infusion. After SO manometry, continuous infusion of somatostatin at a rate of $250 \mu \mathrm{g} / \mathrm{h}$ for 12 hours was started. Basal SO pressure $\geqslant 40$ $\mathrm{mm} \mathrm{Hg}$ was defined as SO dysfunction. Serum amylase, lipase, glucose, and $\mathrm{C}$ reactive protein (CRP) levels were measured before and 12 hours after SO manometry.

The human research committee of Kaohsiung Veterans General Hospital approved the study. The protocol was explained to each patient and written consent was obtained. A paired $t$ test was used to compare values before and after somatostatin infusion in the same patient. Values of $\mathrm{p}<0.05$ were considered significant.

\section{Results}

Patient characteristics are shown in table 1. There were 18 males and two females, aged 26-61 years. Eleven patients had a high serum cholesterol (>200 mg\%) or triglyceride (>200 $\mathrm{mg} \%$ ) level. Ten patients had fever on admission but the fever subsided with conservative treatment before SO manometry. Pancreatitis was graded according to the computed tomography criteria of Balthazar and colleagues ${ }^{17}: 12$ patients had grade $C$, four patients grade D, and four patients grade $\mathrm{E}$.

SO manometry was successfully performed in 14 of 20 patients $(70 \%)$. Deep cannulation of the catheter failed in six patients (all male, mean age 39.7 years, grade $\mathrm{C}$ in two patients, grade $\mathrm{D}$ in three patients, and grade $\mathrm{E}$ in one patient) due to a contracted sphincter. There were no significant differences in age, sex, grading, serum amylase, lipase, glucose, or CRP between the six patients with failed
Table 2 Age, sex, computed tomography (CT) grade, and sphincter of Oddi basal pressure (SOBP) in the 14 patients with acute non-biliary pancreatitis

\begin{tabular}{llllc}
\hline Patient No & Age $(y)$ & Sex & CT grade & $\begin{array}{c}\text { SOBP } \\
(\text { mm Hg })\end{array}$ \\
\hline 1 & 27 & Male & C & 74 \\
2 & 32 & Male & C & 20 \\
3 & 57 & Male & C & 38 \\
4 & 52 & Male & C & 70 \\
5 & 35 & Male & C & 95 \\
6 & 43 & Male & C & 50 \\
7 & 30 & Male & C & 20 \\
8 & 50 & Female & C & 10 \\
9 & 54 & Male & C & 70 \\
10 & 35 & Male & C & 10 \\
11 & 61 & Female & D & 30 \\
12 & 30 & Male & E & 36 \\
13 & 36 & Male & E & 50 \\
14 & 54 & Male & E & 110 \\
\hline
\end{tabular}

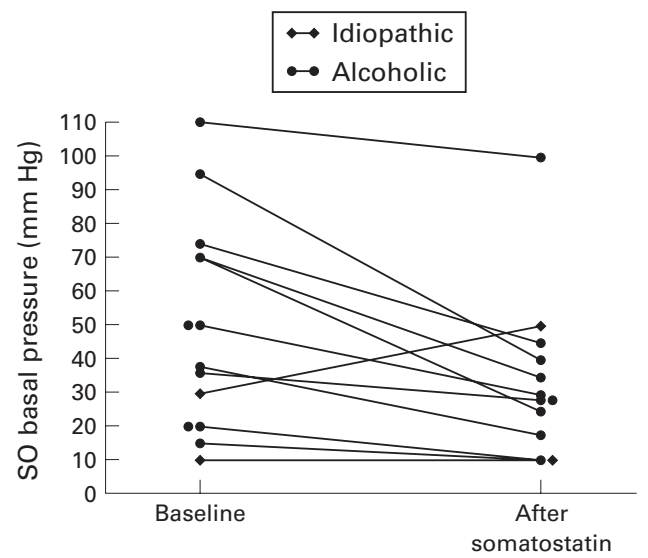

Figure 2 Sphincter of Oddi (SO) basal pressure before and after somatostatin infusion in 14 patients with acute non-biliary pancreatitis.

cannulation and the 14 patients with successful cannulation. In 14 patients with successful SO manometry, cannulation of the pancreatic duct was confirmed by the absence of bile from the catheter after deep insertion.

The results of SO manometry in 14 patients are shown in table 2. SOBP was higher than $40 \mathrm{~mm} \mathrm{Hg}$ in seven patients with alcoholic pancreatitis and three had tonic contraction. After somatostatin infusion, 13 patients had a significant fall in SOBP and one patient with idiopathic pancreatitis had a paradoxical reaction (SOBP rose from 30 to $50 \mathrm{~mm} \mathrm{Hg}$ after somatostatin infusion) (figs 1,2). Mean SOBPs in 14 patients before and after somatostatin infusions were 48.8 (29) $\mathrm{mm} \mathrm{Hg}$ and 31.9 (22) $\mathrm{mm} \mathrm{Hg}$, respectively $(\mathrm{p}<0.01)$. One patient with grade $\mathrm{E}$ alcoholic pancreatitis and an SOBP of $110 \mathrm{~mm} \mathrm{Hg}$ developed severe abdominal pain and marked elevation of serum

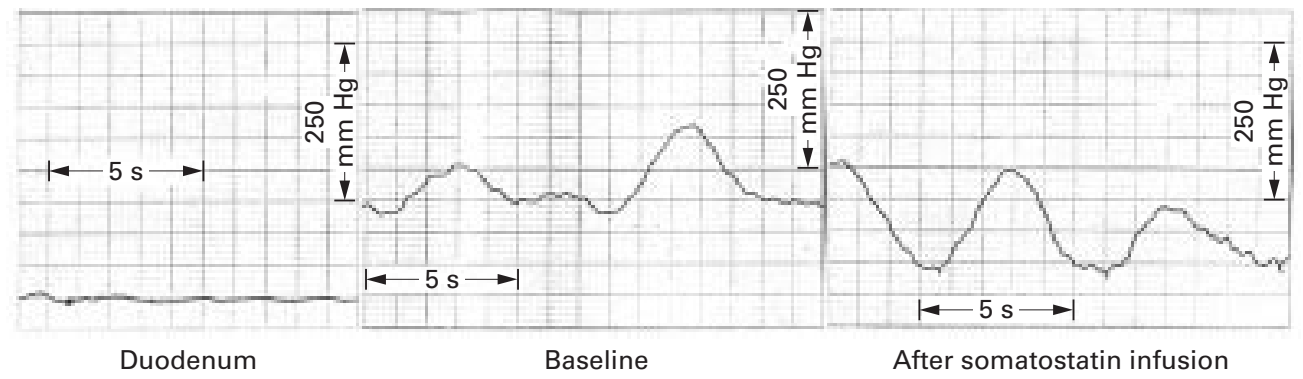

Figure 1 Sphincter of Oddi manometry in patient No 5 before and after somatostatin infusion. 
Table 3 Serum amylase, lipase, fasting glucose, and $C$ reactive protein (CRP) levels before and after sphincter of Oddi manometry (SOM)

\begin{tabular}{llcl}
\hline & Baseline & After SOM & p Value \\
\hline Amylase (U/l) & $397(120)^{\star}$ & $340(130)$ & 0.761 \\
Lipase (U/l) & $800(721)$ & $657(584)$ & 0.190 \\
Glucose (mg/dl) & $156(10)$ & $153(21)$ & 0.881 \\
CRP (mg/dl) & $11.1(4.3)$ & $8.8(5.8)$ & 0.714 \\
\hline
\end{tabular}

Values are mean (SEM)

amylase to $2516 \mathrm{IU} / 1$ (normal < $160 \mathrm{IU} / 1$ ) after SO manometry but symptoms subsided after two weeks of conservative treatment. No additional side effects were found in the other 19 patients. There were no significant differences in mean serum amylase, lipase, glucose, or CRP levels in the 20 patients before and after SO manometry and somatostatin infusion (table 3).

\section{Discussion}

Although SO dysfunction is generally thought to be a cause of acute pancreatitis, the incidence of SO dysfunction in acute pancreatitis is unknown. ${ }^{78}$ The gold standard in evaluation of SO function is SO manometry but it is not routinely used as a diagnostic test for acute pancreatitis due to technical difficulties and the potential complications, particularly postprocedural pancreatitis. ${ }^{71819}$

Cuschieri et al found eight patients with gall stone pancreatitis whose basal pressures of SO were lower than normal. ${ }^{20}$ However, Guelrud et al demonstrated that patients with common bile duct (CBD) stones and recurrent pancreatitis had higher SOBPs than control subjects or patients with CBD stones and no history of pancreatitis. ${ }^{21}$ Basal SO pressures in patients with alcoholic pancreatitis were also different in previous studies. From the results of lowering of SOBP by intravenous and intragastric instillation of alcohol, Viceconte speculated that alcohol could predispose to the development of pancreatitis by allowing pancreaticoduodenal reflux to occur. ${ }^{3}$ Goff reported a non-significant fall in mean basal pancreatic duct sphincter pressure and a significant fall in phasic contraction and mean amplitude after infusion of $80 \mathrm{~g}$ of whisky into the stomach. ${ }^{4}$ However, basal SO pressures in patients with pancreatitis before alcohol infusion were higher than non-pancreatitis patients. ${ }^{4}$ In contrast, Guelrud et al observed tonic SO contraction after local instillation of high concentrated $(40 \%)$ alcohol solution in patients with alcoholic pancreatitis. ${ }^{5}$ Tarnasky et al also reported that patients with SO dysfunction were four times more likely to have evidence of chronic pancreatitis than those without SO dysfunction. ${ }^{22}$

In our study, $50 \%$ of patients with acute non-biliary pancreatitis had high SOBP. If we include the six patients with spastic SO during manometry as abnormal, $13 / 18$ patients $(73 \%)$ with acute alcoholic pancreatitis had abnormal $\mathrm{SO}$ function. The difference in SO function in our patients with alcoholic pancreatitis from that in previous studies may be due to differences in the methods used. Most patients are reluctant to undergo SO manometry during the acute stage of pancreatitis because it is a relatively painful procedure. The timing of SO manometry was not the same in previous studies and some patients underwent SO manometry after the acute inflammation subsided. In addition, isolated elevation of basal pressure of the pancreatic SO or biliary SO may occur independently. Selective cannulation of the pancreatic duct for manometry is important in patients with acute pancreatitis. ${ }^{24}{ }^{24} \mathrm{We}$ performed SO manometry in patients within one week after the onset of acute pancreatitis, and selective cannulation of the pancreatic duct was confirmed by the absence of bile aspiration from the catheter after deep insertion. High SOBP was present in seven of 12 patients with acute alcoholic pancreatitis but none in the two patients with idiopathic pancreatitis, and hence SO dysfunction may be a contributing factor for the pathogenesis of acute alcoholic pancreatitis.

Pancreatic sphincterotomy is helpful in some patients with recurrent pancreatitis. ${ }^{25}$ However, it is still unclear whether the change in SO function in those patients with a first attack of acute alcoholic pancreatitis is a transient abnormality due to inflammation or a permanent event. Further follow up studies, including SO manometry after complete recovery, are necessary.

Somatostatin is a potent inhibitor of pancreatic enzyme secretions and has been used in the treatment of acute pancreatitis. Although some studies have demonstrated the stimulating effect of octreotide, a long acting somatostatin analogue, on SO activity, ${ }^{12} 26$ the native hormone, somatostatin-14, has been shown to inhibit SO activity in several studies..$^{14}{ }^{14}$ In our study, somatostatin reduced SOBP significantly in more than $93 \%$ of patients, and most of those on continuous infusion of somatostatin felt well even after pancreatic cannulation during SO manometry. Somatostatin relaxes the SO allowing free drainage of pancreatic secretions and it may be the drug of choice to alleviate symptoms and reduce the complications of endoscopic retrograde cholangiopancreatography in patients with acute pancreatitis. ${ }^{27}$ The drawbacks of somatostatin include its short acting effect and paradoxical response in some patients. Reflux of duodenal juice after SO relaxation or sphincterotomy rarely occurs. $^{28}$

In conclusion, $\mathrm{SO}$ dysfunction is commonly present in patients with acute alcoholic pancreatitis. Somatostatin can relax the $\mathrm{SO}$ and may be a useful drug in acute alcoholic pancreatitis.

This study was supported by a grant from the National Science Council (NSC 88-2314-B-075B-004) and Serono company. Part of this study was presented at the 7th United European Gastroenterology Week in Rome, Italy, 1999. The authors would like to thank Professor Jules Constant for his help in revision of this manuscript.

1 Alder G, Schoenberg MH. Acute pancreatitis. Curr Opin Gastroenterol 1996;12:429-35.

2 Bank S, Indaram A. Causes of acute and recurrent pancreatitis. Gastroenterol Clin North Am 1999;28:571-89.

3 Viceconte G. Effects of ethanol on the sphincter of Oddi: an endoscopic manometric study. Gut 1983;24:20-7.

4 Goff JS. The effect of ethanol on the pancreatic duct sphincter of Oddi. Am $\mathcal{f}$ Gastroenterol 1993;88:656-60. 
5 Guelrud M, Mendoza S, Tossiter G, et al. Effect of local instillation of alcohol on sphincter or Oddi motor activity: combined ERCP

6 Toouli J, Thomson ICR, Dent J, et al. Sphincter of Oddi motility disorders in patients with idiopathic recurrent pancreatitis. Br F Surg 1985;72:859-63.

7 Kuo WH, Pasricha PJ, Kalloo AN. The role of sphincter of Oddi manometry in the diagnosis and therapy of pancreatic disease. Gastrointest Endosc Clin N Am 1998;8:79-85.

8 Chen JW, Saccone GTP, Toouli J. Sphincter of Oddi dysfunction and acute pancreatitis. Gut 1998;43:305-8.

9 Friess H, Buchler MW. Efficacy of somatostatin and its analogues in pancreatic surgery and pancreatic disorders. Digestion 1996;57(suppl 1):97-102.

10 Jenkins SA, Berein A. The relative effectiveness of somatostatin and octreotide therapy in pancreatic disease. Aliment Pharm Ther 1995;9:349-61.

11 Buchler MW, Binder M, Friess H. Role of somatostatin and its analogues in the treatment of acute and chronic its analogues in the treatment of acute

12 Francesco VD, Angelini G, Bovo P, et al. Effect of octreotide on sphincter of Oddi motility in patients with acute recur-
rent pancreatitis, a manometric study. Dig Dis Sci 1996;41: rent pancice.

13 Baxter JN, Jenkins SA, Day DW, et al. Effects of somatostatin and a long-acting somatostatin analogue on the prevention and treatment of experimentally induced acute pancreatitis in the rat. Br F Surg 1985;72:382-5.

14 Adrendt SA, McGuire CH, Lilemore KD, et al. Somatostatin inhibits sphincter of Oddi motility. Gastroenterology 1990;98:242A

15 Andriulli A, Leandro G, Niro G, et al. Pharmacologic treatment can prevent pancreatic injury after ERCP: a meta-analysis. Gastrointest Endosc 2000;51:1-7.

16 Bordas JM, Toledo-Pimentel V, Llach J, et al. Effects of bolus somatostatin in preventing pancreatitis after endoscopic pancreatography: results of a randomized study. scopic pancreatography: results
Gastrointest Endosc 1998;47:230-4.
17 Balthazar EJ, Robinson DL, Megibow AJ, et al. Acute pancreatitis: value of CT in establishing prognosis. Radiolpancreatitis: value of
ogy $1990 ; 174 ; 331-6$

18 Scicchitano J, Saccone GTP, Baker RA, et al. How safe is endoscopic sphincter of Oddi manometry? $\mathcal{F}$ Gastroenterol Hepatol 1995;10:334-6.

19 Lans JL, Parikh NP, Geenen JE. Application of sphincter of Oddi manometry in routine clinical investigation. Endoscopy 1991;23:139-43.

20 Cuschieri A, Cumming JGR, Wood RAB, et al. Evidence for sphincter dysfunction in patients with gallstone associated with pancreatitis: effect of ceruletide in patients undergoing cholecystectomy for gallbladder disease and gallstones associated pancreatitis. Br F Surg 1984:71:885-8.

21 Guelrud M, Mendoza S, Vicent S, et al. Pressures in the sphincter of Oddi in patients with gallstones, common duct stones, and recurrent pancreatitis. I Clin Gastroenterol 1983;5:37-41.

22 Tarnasky PR, Hoffman B, Aabakken L, et al. Sphincter of Oddi dysfunction is associated with chronic pancreatitis. Am 7 Gastroenterol 1997;92:1125-9.

23 Blackstone MO. Basal sphincter of Oddi pressure never elevated in alcoholic pancreatitis? Dig Dis Sci 1992;37:9612 .

24 Silverman WB, Ruffolo TA, Sherman S, et al. Correlation of basal sphincter pressures measured from the bile duct and the pancreatic duct in patients with suspected sphincter of Oddi dysfunction. Gastrointest Endosc 1992;38:440-3.

25 Toouli J, Saccone DFG, Kollias J, et al. Division of the sphincter of Oddi for treatment of dysfunction associated with recurrent pancreatitis. Br F Surg 1996;83:1205-10.

26 Binmoeller KF, Harris AG, Dumas R, et al. Does the somatostatin analogue octreotide protect against ERCP induced pancreatitis. Gut 1992;33:1129-33.

27 D'Amico D, Favia G, Biasiato R, et al. The use of somatostatin in acute pancreatitis - results of a multicenter somatostatin in acute pancreatitis-results

28 Watanapa P, Williamson RCN. Pancreatic sphincterotomy and sphincteroplasty. Gut 1992;33:865-7. 